\title{
Review of photokeratitis: Corneal response to ultraviolet radiation (UVR) exposure*
}

\author{
LA Moore ${ }^{a}$, , M Hussey ${ }^{b}$, JT Ferreirac ${ }^{c}$ and B Wu ${ }^{d}$
}

a Department of Optometry/National Optometry Centre, Dublin Institute of Technology, Kevin Street, Dublin 8, Republic of Ireland

b Professor Emeritus, Faculty of Science, Dublin Institute of Technology, Kevin Street, Dublin 8, Republic of Ireland

c Department of Optometry, University of Johannesburg, PO Box 524, Auckland Park, 2006, South Africa

d School of Computing, Dublin Institute of Technology, Kevin Street, Dublin 8, Republic of Ireland

$<$ Linda.Moore@dit.ie $>$

Received 26 March 2010; revised paper accepted 30 September 2010

\begin{abstract}
The development of photokeratitis in response to natural solar ultraviolet radiation (UVR) is prevalent in individuals participating in outdoor recreational activities in environments with high reflective surfaces, such as beach activities, water sports and snow skiing. Eye care practitioners (ECPs) are frequently encouraged by manufacturers and researchers to recommend UVR-blocking eyewear in the form of sunglasses and contact lenses. However, little is known about the precise nature of the corneal tissue response in the development of
\end{abstract}

photokeratitis. This paper reviews the mechanisms responsible for the development of photokeratitis. Clinical signs and symptoms of photokeratitis, UVR corneal threshold and action spectra, corneal cellular changes and ocular protection from corneal UVR exposure are discussed. The content of this article will be useful to ECPs in making appropriate recommendations when prescribing UVR-protective eyewear. (S Afr Optom 2010 69(3) 123-131)

Key words: Ultraviolet radiation (UVR), photokeratitis, cornea and corneal physiology

\section{Introduction}

Although only approximately $5 \%$ of solar ultraviolet radiation (UVR) (electromagnetic radiation ranging from $200 \mathrm{~nm}$ to $400 \mathrm{~nm}$ ) reaches the earth's surface, it plays a significant biological role ${ }^{1}$. This UVR consists of short-wavelength, high-energy photons that have sufficient energy to cause photochemical

a BOptom MPhil PhD PGCert (Clin Optom)

b BE MSc PhD

c BOptom $\mathrm{PhD}$

d BSc MSc PhD

* This review was carried out as part of research for the degree of Doctor of Philosophy (PhD) at the Dublin Institute of Technology undertaken by LA Moore with the guidance of Professors M Hussey and JT Ferreira and Dr B Wu. 
common of these ophthalmohelioses is the corneal inflammatory condition, photokeratitis ${ }^{2}$, which can lead to considerable discomfort, blurring and distraction for the affected individual. It is important that the eyecare practitioner (ECP) understands the underlying mechanisms of the corneal response to UVR exposure, so that appropriate recommendations can be made concerning UVR-protective contact lenses and sunglasses, particularly for outdoor natural solar UVR exposure conditions.

\section{Clinical signs and symptoms of photokeratitis}

Clinical signs of photokeratitis include: conjunctival and circumlimbal injection, epithelial granulation, irregular corneal reflex, corneal oedema, bilateral punctate keratitis, epithelial desquamation, pupillary miosis, conjunctival chemosis, anterior uveitis and aqueous flare $6,16,17$. Symptoms include: pain $^{7,8}$, foreign body sensation, photophobia, lacrimation and blepharospasm. These acute symptoms may occur in varying degrees and usually last six hours to 24 hours, but almost all of the discomfort disappears within 48 hours ${ }^{1,12,18}$. The effects of photokeratitis can cause the individual to be visually incapacitated for varying periods of time ${ }^{2,19}$.

The ocular discomfort and visual interference associated with the development of photokeratitis have potential safety implications for the individual and others within the outdoor environment. They can also adversely affect sporting and other recreational performance in conditions of natural solar UVR exposure ${ }^{17}$. It is likely that many individuals frequently experience mild forms of this condition, but do not seek medical attention, as they attribute the tired, sore, gritty ocular feeling experienced after a day outdoors to general fatigue. This could be related to the fact that thermal injury could result at radiant exposures less than those required for photochemical injury ${ }^{20}$. These signs and symptoms are better understood if the underlying principles concerning the corneal tissue response to UVR are considered.

\section{UVR absorption features of corneal tissue}

The corneal tissue shows a wavelength-dependent absorption of UVR ${ }^{19}$. It absorbs most of UVR in the UVC portion (280-200 nm) of the spectrum, with less absorption in the UVB (320-280 nm) and UVA (400-
$320 \mathrm{~nm}$ ) wavebands. Between $2 \%$ and $17 \%$ of ambient UVB is estimated to be incident at the anterior corneal surface, of which $40 \%$ to $70 \%$ is absorbed by the corneal tissue ${ }^{21}$. Approximately $3 \%$ to $8 \%$ of UVB is transmitted by the cornea to the internal ocular structures. Of the UVA incident at the corneal surface, $40 \%$ to $60 \%$ is transmitted through the cornea, to the anterior surface of the crystalline lens ${ }^{22}$. According to the ICNIRP (The International Commission on Non-Ionizing Radiation) (2004) $)^{1}$, there is a lack of evidence to prove whether low levels of UVA experienced in sunlight present a hazard to either the skin or the eye. It is important to note that just because there is currently a lack of evidence for this effect, it does not mean that no UVA hazard exists.

\section{Corneal UVR thresholds and action spectra}

Each UVR-induced biological reaction has a defined threshold dose and action spectrum ${ }^{23}$. The corneal threshold curve and associated action spectra are employed in dosimetric studies for the quantification of corneal tissue damage associated with UVR exposure ${ }^{10,24}$. The threshold dose is the smallest dose of monochromatic radiation at a given wavelength that is sufficient to induce tissue damage ${ }^{3,19}$ and depends on the wavelengths of the UVR absorbed. Suprathreshold corneal epithelial UVR exposure typically leads to the development of photokeratitis.

Corneal tissue UVR-induced injury thresholds can be extrapolated from acute animal exposure experiments ${ }^{25}$. The ICNIRP 2004 guidelines state that extrapolations from animal, particularly primate ${ }^{1}$, experiments to potential or likely effects on humans have to be made due to ethical and practical reasons. Photons in the UVB range contain sufficient energy to cause transformations of absorbing molecules in short exposure times with high (relative to outdoor solar UVR) UVR radiation irradiances obtainable in the laboratory. This has allowed laboratory studies to be conducted relatively quickly with animal ocular tissues $^{26}$.

Corneal tissue thresholds to UVR can be presented either as the threshold values at specific wavelengths within a band of UVR, or as a single peak threshold value. Human, primate and rabbit corneal threshold values reported from previous studies are summarised in Figure 1 below. 


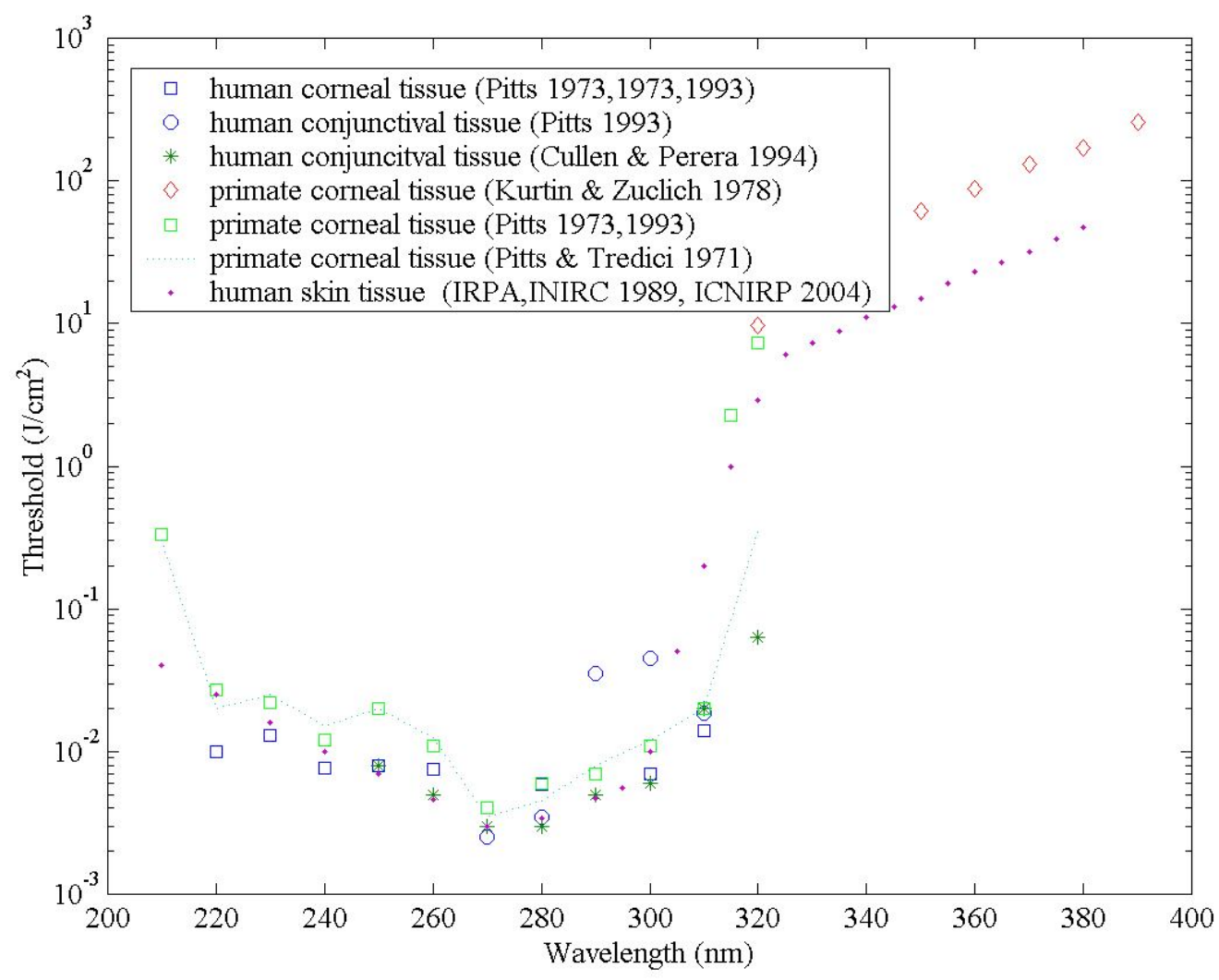

Figure 1. Published corneal, conjunctival and skin UVR threshold values.

A study carried out by Pitts and Tredici27 in 1971 showed that the minimum of the UVR threshold curve is at $270 \mathrm{~nm}$ for both the rabbit and primate corneas. Threshold data by Pitts ${ }^{19,28}$ in 1973 and 1974 are presented at the median wavelength. That is, in these publications, the data are presented in wavebands of $10 \mathrm{~nm}$, for example, $205 \mathrm{~nm}$ to $215 \mathrm{~nm}$. These are plotted on the graph above showing a threshold at 210 $\mathrm{nm}$. The corneal tissue threshold values for primates and rabbits are included in this plot as there are limited published data sets for human subjects after 1973 due to more stringent ethical research restrictions being in place to prevent the irradiation of a human eye with potentially harmful UVR. The published threshold values for primates are therefore also considered. The corneal threshold data for rhesus monkeys obtained by Kurtin and Zuclich ${ }^{29}$ in 1978 are presented for a waveband of $320 \mathrm{~nm}$ to $390 \mathrm{~nm}$, at $10 \mathrm{~nm}$ intervals. Some of the references quoted were published during the 1970s, but the results of these publications still remain relevant, as shown by their inclusion in the 2004 ICNIRP guidelines, which is its most recent publication concerning the potentially harmful effects of UVR exposure on human tissue ${ }^{1}$. The variability of data contained in these publications could be due to differences in experimental methodologies, in particular the total irradiance, spectral irradiance and waveband under investigation. Unfortunately none of the references cited provided detailed methodological descriptions to facilitate further analysis of the results obtained. There is need for further systematic measurements in these fundamental areas.

Furthermore, published data for corneal epithelial thresholds are given for a variety of waveband intervals and wavelength intervals. The reason for this could be that the human action spectra are assumed to lie only within the waveband limits tested. This is particularly true of early publications, such as that of Pitts ${ }^{19,28}$. Pitts studied the effects of UVR energy on the exposed live human eye ${ }^{19,28}$. The object of this study was to establish the UVR action spectra in the human cornea. In this study, 39 human eyes were exposed to UVR from $220 \mathrm{~nm}$ to $310 \mathrm{~nm}$, in $10 \mathrm{~nm}$ waveband intervals. In the study, the human UVR action spectrum was compared to the previously established rabbit and primate UVR action spectra. The main limitation of the work was that the data were collected only in the UVC and part of the UVB bands. This limits the rigorous use of these data for dosimetric applications in the $220 \mathrm{~nm}$ to $310 \mathrm{~nm}$ waveband. 
The threshold data were collected at $10 \mathrm{~nm}$ intervals only, thus further limiting their usefulness for accurate dosimetry.

Accurate dosimetry requires narrower wavelength intervals. Pitts ${ }^{19,28}$ showed the rabbit exposure threshold at $270 \mathrm{~nm}$ to be $0.005 \mathrm{~J} / \mathrm{cm}^{2}$. The rabbit curve had two minima, at $240 \mathrm{~nm}$ and $270 \mathrm{~nm}$. The 270 $\mathrm{nm}$ radiant exposure threshold for the primate cornea was quoted as $0.004 \mathrm{~J} / \mathrm{cm}^{2}$. The primate curve has three minima, at $220 \mathrm{~nm}, 240 \mathrm{~nm}$ and $270 \mathrm{~nm}$. Both the rabbit and primate curves show steep increases in threshold below $220 \mathrm{~nm}$ and above $310 \mathrm{~nm}$. According to Pitts, the human corneal UVR threshold curve is not as easily defined as are those for rabbit and primate corneas. At $270 \mathrm{~nm}$, the minimum corneal threshold value of $0.004 \mathrm{~J} / \mathrm{cm}^{2}$ given for the human cornea was the same as that for the primate. At 260 $\mathrm{nm}$ and above, the human threshold curve is similar to that of the primate. Below $250 \mathrm{~nm}$, the human threshold curve shows radiant exposure threshold values below that obtained for the rabbit and primate corneas. Rather than showing minima, the human corneal threshold curve tends to be shallow. The likely reason for human thresholds below $250 \mathrm{~nm}$ being flatter or shallower than those obtained for primates is that at wavelengths of $250 \mathrm{~nm}$ and below, exposure limits equal to that of a primate cause discomfort for a human subject. Therefore, for those wavebands, Pitts used exposures of $40 \%, 50 \%$ or $60 \%$ of the primate threshold.

Ahmedbhai and Cullen ${ }^{30}$, Australian HMRC ${ }^{31}$, Quesnel and Simonet ${ }^{32}$ and Quesnel et al $^{33}$ specify the peak corneal epithelial damage threshold at $270 \mathrm{~nm}$ to be $0.003 \mathrm{~J} / \mathrm{cm}^{2}$. Sliney ${ }^{34}$ uses a corneal tissue threshold value of $0.005 \mathrm{~J} / \mathrm{cm}^{2}$. Schein ${ }^{35}$ also specifies a value of $0.005 \mathrm{~J} / \mathrm{cm}^{2}$, while Ambach and Blumthaler $^{23}$ and Pitts and Lattimore ${ }^{36}$ adopt a value of 0.004 $\mathrm{J} / \mathrm{cm}^{2}$. The ICNIRP ${ }^{1}$ puts the value at $0.003 \mathrm{~J} / \mathrm{cm}^{2}$. Bergmanson et $a^{37}$ found a corneal damage threshold for the $300 \mathrm{~nm}$ wavelength to be $0.08 \mathrm{~J} / \mathrm{cm}^{2}$. According Cullen and Perera ${ }^{2}$, corneal injury from UVA wavelengths requires levels exceeding $10 \mathrm{~J} / \mathrm{cm}^{2}$.

In 2004, Čejkova et $a l^{38}$, Rogers et $a^{39}$ and Shimmura et al $^{40}$ demonstrated subclinical corneal physiological and biochemical changes that may occur as a result of excess corneal UVR exposure. The purpose of the study by Rogers et $a l^{39}$ was to establish whether exposing cultured rabbit corneal and epithelial cells to
UVR equivalent to several hours under the sun would damage the cells. Cells were exposed to a maximum dose of $6.3 \mathrm{~J} / \mathrm{cm}^{2}$ of UVA (320 nm to $400 \mathrm{~nm}$ ) and $6.3 \mathrm{~J} / \mathrm{cm}^{2}$ of UVB (290 nm to $\left.320 \mathrm{~nm}\right)$, with levels of UVA and UVB irradiation increasing over the course of the exposure time. Both UVA and UVB caused cell death in corneal epithelial cells with different latent periods. Minimal levels of cell death occurred immediately after exposure to UVB, increasing to a level of $46 \%$ of cell death after a period of 5 hours of exposure, with the irradiance reaching a level of 0.60 $\mathrm{J} / \mathrm{cm}^{2}$. When corneal cells were irradiated with UVA, at $6.3 \mathrm{~J} / \mathrm{cm}^{2}$ of exposure, $37 \%$ of the cells had undergone physiological changes. The study concluded that even sub-solar levels of corneal exposure to solar UVR leads to corneal epithelial cell death. Similarly, Podskochy et al ${ }^{41}$ showed that corneal epithelial cell death occurred after rabbit corneas were exposed to $0.47 \mathrm{~J} / \mathrm{cm}^{2}$ of $310 \mathrm{~nm}$ UVB irradiation.

Threshold values for the human skin are also plotted in Figure 1. These are included because they are often erroneously quoted in ocular dosimetric publications. The most common of these involve the use of spectroradiometers to measure UVR incident at the earth's surface or ocular surface. These spectroradiometers are erythemally weighted. This means that they give results based on the human skin action spectrum $^{42 .} 43$.

Blumthaler et al ${ }^{44}$ modelled threshold radiant exposures based on interviewing patients presenting with photokeratitis, in order to accurately specify their exposure times. The results of the study showed that the threshold for photokeratitis is $0.12 \mathrm{~J} / \mathrm{m}^{2}$. The conclusion is not quantified in terms of the UVR wavelength(s) at which the effect was caused. Nevertheless this is a significantly higher value than those published by other authors. This may be due to the fact that the results of other corneal studies discussed in this paper were obtained by means of direct irradiation of the cornea in an environment simulating solar UVR. The result obtained by Blumthaler et $a l^{44}$ may reflect a more natural outdoors exposure condition, where patient movement and geometry of exposure would influence (and effectively reduce) the actual exposure of the corneal tissue. The authors suggest that partial closure of the eyelids due to blinking and squinting would lead to an approximately $50 \%$ reduction of the radiant exposure of the eye. Taking 
such factors into account leads to an estimated corneal threshold value of 0.03 to $0.06 \mathrm{~J} / \mathrm{cm}^{2}$. This result therefore shows the likelihood of a higher threshold value for the development of photokeratitis in response to solar UVR in practical conditions.

The action spectrum indicates the relative biological effectiveness of monochromatic radiation of different wavelengths to elicit a response in tissue. An action spectrum is normalised to $100 \%$ at the minimum 23,25 . This means that the point on the corneal threshold curve representing the minimum dose of UVR, is allocated a value of $100 \%$, with all other points being plotted relative to this $100 \%$ (or 1.0 ) value. Action spectra are important because they permit one to estimate a relative risk value on exposure to different sources that emit different distributions of $\mathrm{UVR}^{25}$. When assessing the relative risk of development of photokeratitis, the action spectrum is usually normalised to $100 \%(1.0)$ at $270 \mathrm{~nm}$, the wavelength requiring the minimum dose to produce photokeratitis ${ }^{19,28}$. The threshold measured at that point, 0.003 $\mathrm{J} / \mathrm{cm}^{2}$, is given a value of 1.0 and the other threshold data for the other UVR wavelengths are weighted accordingly. The biological effectiveness of UVR at a particular wavelength is inversely proportional to the threshold dose at that wavelength ${ }^{1,5,7,10,19,23,28,29,45-50}$.

The $270 \mathrm{~nm}$ wavelength identified for normalisation for calculation of the action spectrum for human corneal tissue falls in the UVC range, outside the solar UVR spectrum ${ }^{423,34,44}$. For this reason, it was proposed by Kurtin and Zuclich ${ }^{29}$ that the corneal epithelial threshold value obtained at $320 \mathrm{~nm}$ should be used for corneal dosimetry. This recommendation is based on the results of their study on rhesus monkeys, which showed that the corneal threshold decreases monotonically with wavelength throughout the near UVR, exhibiting a pronounced shoulder in the 340 to $350 \mathrm{~nm}$. This would be more indicative of practical outdoor exposure situations than weighting the corneal threshold at $270 \mathrm{~nm}$, which is less indicative of natural solar conditions since this wavelength does not reach the surface of the earth. They showed that the corneal tissue threshold value is $0.000096 \mathrm{~J} / \mathrm{cm}^{2}$ at $320 \mathrm{~nm}$ for the rhesus monkey cornea. In a later publication, Schein ${ }^{35}$ proposed that at $320 \mathrm{~nm}, 10 \mathrm{~J} / \mathrm{cm}^{2}$ is required to produce photokeratitis. The difference in the threshold values presented by these authors is highly significant. The value presented by Schein was offered in a general discussion about ocular phototoxicity and did not provide any measured data to support the proposal. The publication of Kurtin and Zuclich $^{29}$, albeit older, presented supporting measured data and may therefore be regarded as having higher reliability and validity.

The corneal tissue action spectrum is required for use in the computation of the safe exposure duration (SEDs) and protection factors (PFs) associated with exposure to solar UVR and the assessment of the efficacy of soft contact lenses in providing the cornea with protection from the adverse effects of UVR and has been applied in other publications ${ }^{1,2,31,51-54}$.

\section{UVR-induced corneal cellular changes}

\section{Epithelial changes}

The corneal epithelium absorbs most of the UVA absorbed by the cornea. The epithelium is the most anterior of the corneal layers and is therefore exposed to UVR first. Physical or radiation insults may lead to sloughing of corneal epithelial cells and an associated increase in the UVR-absorption by corneal tissue $8,9,13,55$. If such damage remains isolated to the epithelial layer, then the damage is considered reversible, as epithelial cells have the ability to repair the damage to restore the original function of the cornea ${ }^{6-9}, 13,16-18,20$. Exfoliation of corneal epithelial cells occurs when a threshold dose of UVR is reached. This manifests as shedding and apoptosis of cells, which is accelerated by UVR exposure. Supra-threshold UVR exposure can result in full thickness loss of the stratified epithelium to the basement membrane. This can cause the nerve endings to be exposed, manifesting as ocular pain 7,8 . This was also the finding of Bergmanson et al ${ }^{37,56}$, who showed that in an unprotected rabbit eye exposed to light from a UVR lamp, there was full thickness epithelial loss, as well as loss of keratocytes and endothelial cells. The basement membrane remained intact, thus facilitating epithelial repair and limbal stem cells outside of the exposure zone slid over the basement membrane to repair the epithelial defect.

\section{Stromal changes}

The destruction of endothelium by UVR may result in marked swelling of the corneal stroma by as much as $200 \% 57$. The stromal swelling that may occur in response to UVR exposure leads to a disruption 
of the regular arrangement of collagen fibrils within the cornea and the associated opacification of the cornea. This disruption of the fibril arrangements leads to visual blurring ${ }^{57}$. This swelling also leads to an increased thickness of the cornea leads, resulting in a change in the refractive power of the cornea, manifesting as a myopic shift. This means that it effectively makes the person more short-sighted and less able to see objects at a distance, thus further impairing vision. This effect is reversible if the source of stress, for example a contact lens or excess UVR exposure, is removed ${ }^{7,36,55}$. Recovery of corneal thickness after UVR exposure takes approximately 72 hours. It is generally assumed that this reversibility holds for all wavelengths and exposures ${ }^{20}$.

\section{Endothelial changes}

The corneal endothelial structure and function can be damaged due to exposure to UVB. Endothelial cells are non-mitotic and therefore cannot be regenerated once damaged or lost. This may lead to the formation of guttata, which are small nodules in Descemet's membrane formed by the bulging of the endothelium below. Some eyes may develop a more serious form of endothelial dystrophy if excessive UVR exposure occurs, called Fuch's dystrophy. This endothelial destruction is unlikely to occur at the levels of UVR normally found in outdoor environments.

Cullen ${ }^{7}$ presented data on the corneal endothelial response to UVR and found the threshold dose to be $0.125 \mathrm{~J} / \mathrm{cm}^{2}$. The 1977 publication by Pitts et $a l^{58}$ summarises previous findings by Verhoeff et al. Here, Verhoeff showed that the threshold exposure for wavelengths greater than $295 \mathrm{~nm}$ was $37.8 \times 10-3 \mathrm{~J} /$ $\mathrm{cm}^{2}$ for the rabbit cornea when exposed to UVR from a quartz mercury lamp. This exposure threshold was reached in three minutes. The study also showed that the corneal endothelium was destroyed when it was exposed to wavelengths longer than $295 \mathrm{~nm}$ for six minutes to 12 minutes. The corresponding radiation exposures for these exposure times are $75.6 \times 10-3 \mathrm{~J} /$ $\mathrm{cm}^{2}$ and $152.0 \times 10-3 \mathrm{~J} / \mathrm{cm}^{2}$ respectively. Pitts et al 57 also quote the results of Fischer et al who established a corneal threshold of $0.45 \mathrm{~J} / \mathrm{cm}^{2}$ for the rabbit eye at $350 \mathrm{~nm}$.

\section{Duration of UVR exposure}

It is estimated that 200 seconds of un-attenuated exposure to solar UVB within the $295 \mathrm{~nm}$ to $315 \mathrm{~nm}$ waveband may result in photokeratitis ${ }^{13}$, although the signs and symptoms may still go unnoticed at this point, as they remain sub-clinical. A latent period follows the period of supra-threshold exposure. This represents the length of time that occurs between initial exposure to UVR and the onset of changes in corneal tissue. The latency may last between 30 minutes and 24 hours, with an average of six hours to 12 hours in duration and is commonly assumed to describe the period prior to onset of clinically recognisable corneal changes. More recent research ${ }^{38-40}$ shows that the latent period may need to be redefined with reference to the onset of pre-clinical symptoms, as it has been illustrated that the onset of corneal cellular changes in response to UVR exposure occurs much earlier than was previously proposed by other researchers, that is, the latent period is much shorter than previously thought. The safe exposure duration (SED) for corneal tissue in response to UVR exposure has been modelled ${ }^{52}$ and will form the basis of a future publication.

\section{Long-term effects of UVR exposure}

Repeated exposure of the cornea to potentially hazardous levels of UVR is not believed to increase the protective capability of the cornea, whereas skin tanning is known to increase the protective capability of the $\operatorname{skin}^{1,2,19}$. The effects of repeated exposures tend to be cumulative only when there has been no repair or replacement of the damaged tissue during the time between exposures ${ }^{59}$. There remains uncertainty as to whether there are any long-term corneal effects associated with repeated episodes of photokeratitis. Repeated, severe episodes of photokeratitis may increase the risk of delayed corneal pathologies such as pterygium and droplet keratopathies ${ }^{46}$.

\section{Photoconjunctivitis}

Photokeratitis is generally accompanied by photoconjunctivitis. When this occurs, the individual is said to be manifesting photokeratoconjunctivitis ${ }^{23}$. 
Anatomical and physiological differences between the cornea and conjunctiva may result in different patient symptoms and signs associated with UVR-induced changes in these structures. The same degree of discomfort was not produced by photoconjunctivitis as by photokeratitis. Photoconjunctivitis produces chemosis and damage only to superficial epithelial cells ${ }^{2}$. The data published by Cullen and Perera ${ }^{2}$ provides thresholds for the range $250 \mathrm{~nm}$ to $330 \mathrm{~nm}$, which excludes the UVA portion of the spectrum. The data of Pitts ${ }^{33}$ give conjunctival tissue values from $270 \mathrm{~nm}$ to $310 \mathrm{~nm}$. Cullen and Perera ${ }^{2}$ irradiated the inferior bulbar conjunctivae of 64 human volunteers. This irradiation encompassed the waveband $250 \mathrm{~nm}$ to $330 \mathrm{~nm}$ at $10 \mathrm{~nm}$ intervals. An irradiance level of $125 \mathrm{~mJ} / \mathrm{cm}^{2}$ produced no biological response at $330 \mathrm{~nm}$. The time of exposure needed to produce a higher radiation exposure was considered too long for the subjects to maintain a steady fixation. The action spectrum for conjunctival tissue was found to closely follow that of the cornea, with a maximum response at about $270 \mathrm{~nm}$. This study found threshold radiant exposures for a conjunctival response to be slightly lower than those reported for the human cornea at all wavebands up to $310 \mathrm{~nm}$.

\section{Ocular protection from corneal UVR exposure}

Attenuation of the UVR incident at the anterior ocular surface is the main technique used to prevent absorption of UVR by ocular tissues, thus reducing the risk of development of some sunlight-related eye diseases. The two most common forms of ophthalmic attenuators of UVR radiation are sunglasses and contact lenses. Spectacles with UVR-blocking lenses offer limited ocular protection. The human eye receives 10 to $25 \%$ of the UVR dose when wearing lenses opaque to the UVR compared to the eye without the lens. This applies even when a lens with complete UVR absorption is worn ${ }^{60}$. The UVR is incident at the ocular surface either after transmittance through the lens itself, or by being obliquely incident around the edge of the lens. This oblique incidence is termed a 'non-lens pathway'. The eye is therefore exposed to UVR from the side (laterally), behind (light is reflected off the back surface of the lens and into the eye) and below, leaving the lateral cornea and conjunctiva exposed. Relative contri- butions of these pathways depend on lens material, size and vertex distance $5.10-13.30 .34 .55 .60-64$. The wearing of dark sunglass lenses reduces aversion strategies such as squinting, thereby exposing the eye to more incoming radiation. It is for this reason that sunglasses should not only have sufficient UVR filtration, but should also be of a wrap-around design to prevent UVR being incident at the ocular surface due to these non-lens pathways.

The wearing of a soft contact lens UVR-absorbing material helps to ensure absorption of most ambient UVR that might otherwise enter the eye by bypassing sunglasses or being reflected from the inner surface of sunglasses, through as 'non-lens pathways' 6,65 . This is because of the large diameter of a soft contact lens covering the limbal region and the intimate placement of the lens on the cornea. The amount of UVR irradiance absorbed and transmitted by a lens varies between brands and materials and there is a wide variability between those of different manufacturers. The UVR transmittance curves have been published elsewhere $^{33,51.58 .63-70 .}$.

Understanding the corneal response to UVR radiation and the UVR-protective eyewear that can be used to protect the cornea from the effects of this natural radiation encountered in outdoor recreational environments forms an important basis for ECPs when recommending and prescribing such UVR-protective eyewear for their patients.

\section{References}

1. International Commission on Non-Ionizing Radiation Protection (ICNIRP). Guidelines on limits of exposure to ultraviolet radiation of wavelengths between $180 \mathrm{~nm}$ and 400 nm (incoherent optical radiation). Health Physics 200487 171-186.

2. Cullen AP, Perera SC. Sunlight and the human conjunctival action spectrum. Ultraviolet Radiation Hazards 1994 2134B 24-30.

3. International Radiation Protection Association (IRPA). Guidelines of limits of exposure to ultraviolet radiation of wavelengths between 180 and $400 \mathrm{~nm}$. Health Physics 1985 49 331-340.

4. IRPA/INIRC. Proposed change to the IRPA 1985 guidelines on limits of exposure to ultraviolet radiation. Health Physics 198956 971-972.

5. Sliney DH. Dosimetry for ultraviolet radiation exposure of the eye. Ultraviolet Radiation Hazards 1994 2134B 2-11.

6. Bergmanson JPG, Sheldon T. Ultraviolet radiation revisited. CLAE 199723 96-204. 
7. Cullen AP. Photokeratitis and other phototoxic effects on the cornea and conjunctiva. Int J Toxicol 200221 455-464.

8. Batham G. UV exposure and the eye. Br J Optom Disp 1994 2 366-368.

9. Young AR. Acute effects of UVR on human eyes and skin. Progress in Biophys Mol Biol 200692 80-85.

10. Bergmanson JPG, Söderberg PG. The significance of ultraviolet radiation for eye diseases. Ophthal Physiol Opt 1995 15 83-91.

11. Sliney DH. Geometrical assessment of ocular exposure to environmental UV radiation - Implications for ophthalmic epidemiology. J Epidem 19999 S22-32. [Suppl]

12. Fris M, Cejková J, Midelfart A. Changes in aqueous humour following single or repeated UVR irradiation of rabbit cornea. Graefes Arch Clin Exp Ophthalmol 2007245 1705-1711.

13. Dolin PJ, Johnson GJ. Solar ultraviolet radiation and ocular disease: a review of the epidemiological and experimental evidence. Ophthal Epidemiol 19941 155-164.

14. Pitts DG, Bergmanson JPG. The UV problem: Have the rules changed? J Am Optom Assoc 198960 420-424.

15. Roberts JE. Ocular phototoxicity. Photochem Photobiol 200164 136-143.

16. Young S, Sands J. Sun and the eye: Prevention and detection of light-induced disease. Clin Dermatol 199816 477-485.

17. Friedlander MH. Ultraviolet radiation and the external eye. Int Ophthalmol Clinic 200545 49-54.

18. Oliva MS, Taylor H. Ultraviolet radiation and the eye. Int Ophthalmol Clinic 200545 1-17.

19. Pitts DG. The human ultraviolet action spectrum. Am J Optom Physiol Opt 197451946.

20. Sheedy JE, Edlich RF. Ultraviolet eye radiation: The problem and solutions. J Long-Effects Med Imp 200414 67-71.

21. Rosenthal FS, Safran M, Taylor HR. The ocular dose of ultraviolet radiation from sunlight exposure. $J$ Photochem Photobiol 198542 163-171.

22. Andley UP, Lewis RM, Reddan JR, Kochevar IE. Action spectrum for cytotoxicity in the UVA- and UVB- wavelength region in cultured lens epithelial cells. Invest Ophthalmol Vis Sci 199435 367-373.

23. Ambach W, Blumthaler RB. Biological effectiveness of solar UV radiation in humans. Experentia 199349 747-753.

24. Cullen AP. Photokeratitis and other phototoxic effects on the cornea and conjunctiva. Int J Toxicol 200221 455-464.

25. Sliney DH. Photoprotection of the eye - UV radiation and sunglasses. J Photochem Photobiol 200164 166-175.

26. Faubl H, Quinn MH. Spectra of UV-absorbing contact lenses: relative performance ICLC 200027 65-74.

27. Pitts DG, Tredici TJ. The effects of ultraviolet on the eye. Am Ind Hyg Ass J 197132 235-246.

28. Pitts DG. The ocular ultraviolet action spectrum and protection criteria. Health Physics 197325 559-566.

29. Kurtin WE, Zuclich JA. Action spectrum for oxygen-dependent near-ultraviolet induced corneal damage. J Photochem Photobiol 197827 329-333.

30. Ahmedbhai N, Cullen AP. The influence of contact lens wear on the corneal response to ultraviolet radiation. Ophthal Physiol Opt $1988 \mathbf{8}$ 183-189.
31. Australian Radiation Laboratory on behalf of the Australia National Health and Medical Research Council (ANHNRC)/Department of Community Services and Health. Occupational standard for exposure to ultraviolet radiation. Rad Health Ser 291989.

32. Quesnel N-M, Simonet P. Spectral transmittance of UV-absorbing soft and rigid gas permeable contact lenses. Optom Vis Sci 199572 2-10.

33. Quesnel N-M, Fares F, Verret E, Giasson C. Evaluation of the spectral transmittance of UV-absorbing disposable contact lenses. CLAO 200127 23-29.

34. Sliney DH. Physical factors in cataractogenesis: ambient ultraviolet radiation and temperature Invest Ophthalmol Vis Sci 198627 78-90.

35. Schein OD. Phototoxicity and the cornea. J Nat Med Assoc 199284 579-583.

36. Pitts DG, Lattimore MR. Protection against UVR using the Vistakon UV-Bloc Soft Contact Lens. ICLC 198714 2229.

37. Bergmanson JPG, Pitts DG, Chu LW-F. Protection from harmful UV radiation by contact lenses. J Am Opt Assoc 198859 178-182.

38. Čejkova J, Štipek S, Crkovska J, Ardan T, Plátenik J, Čejka $\breve{C}$, Midelfart A. UV rays, the prooxidant/antioxidant imbalance in the cornea and oxidative eye damage. Physiol Res 200453 1-10.

39. Rogers CS, Chan L-M, Sims YS, Byrd KD, Hinton DL, Twining SS. The effects of sub-solar levels of UV-A and UV-B on rabbit corneal and lens epithelial cells. Exp Eye Res 200478 1007-1014.

40. Shimmura S, Tadano K, Tsubota K. UV dose-dependent caspase activation in a corneal epithelial cell line. Curr Eye Res 200428 85-92.

41. Podskochy A, Gan L, Fagerholm P. Apoptosis in UV-exposed rabbit corneas. Cornea 200019 99-103.

42. Roy CR, Gies HP, Lugg DJ, Toomey S, Tomlinson DW. The measurement of solar ultraviolet radiation Mut Res 1998 422 7-14.

43. Walsh JE, Bergmanson JPG, Saldana Jr, G, Gaume A. Can UV radiation-blocking soft contact lenses attenuate UV radiation to safe levels during summer months in the Southern United States? Eye and Contact Lens 200329 S174-179.

44. Blumthaler M, Ambach W, Daxecher F. On the threshold exposure for keratitis solaris. Invest Ophthalmol Vis Sci 198728 1713-1716.

45. Taylor HR, West SK, Rosenthal FS, Munoz B, Newland HS, Emmett EA. Corneal changes associated with chronic UV irradiation. Arch Ophthalmol 1989107 1481-1484.

46. Sliney DH. Ultraviolet radiation effects upon the eye. Rad Prot Dos 199772 176-206.

47. Sliney DH. How light reaches the eye and its components. Int J Toxicol 200221 501-509.

48. Horneck G. Quantification of the biological effectiveness of environmental UV radiation. J Photochem Photobiol 1995 B31 43-49.

49. Driscoll CMH. Solar UVR measurements. Rad Prot Dos 199664 179-188. 
50. Mentor JM, Hatch L. Clothing as solar radiation protection. Curr Probl Dermatol 200331 50-63.

51. Moore LA, Ferreira JT. Ultraviolet (UV) transmittance characteristics of daily disposable and silicone hydrogel contact lenses. CLAE 200629 115-122.

52. Moore, LA. Corneal Solar Ultraviolet Radiation (UVR) Dosimetry and Computerised Quantification of UVR-Protective Effects of Soft Contact Lenses. PhD Dissertation, Dublin Institute of Technology, Ireland, 2008.

53. Rosenthal FS, Safran M, Taylor HR. The ocular dose of ultraviolet radiation from sunlight exposure. $J$ Photochem Photobiol 198542 163-171.

54. Roy CR, Gies HP, Lugg DJ, Toomey S, Tomlinson DW. The measurement of solar ultraviolet radiation. Mutation Research 1998422 7-14.

55. Cullen AP, Oriowo OM, Voisin AC. Anterior eye focusing of peripheral ultraviolet and visible radiation albedo. Clin Exp Optom 199780 80-86.

56. Bergmanson JPG, Pitts DG, Chu LW-F. The efficacy of a UV-blocking soft contact lens in protecting the cornea against UV radiation. Acta Ophthalmol 198765 279-286.

57. Pitts DG, Cullen AP, Hacker PD. Ocular effects of near ultraviolet radiation: Literature Review. Am J Optom Physiol Opt 197754 542-549.

58. Harris MG, Haririfar M, Hirano KY. Transmittance of tinted and UV-blocking disposable contact lenses. Optom Vis Sci 199976 177-180.

59. Zuclich JA. Cumulative effects of near-UV induced corneal damage. Health Physics 198038 833-838.

60. Sliney DH. UV radiation ocular exposure dosimetry. Doc Ophthalmol 199588 243-254.

61. Rosenthal FS, Bakalian AE, Lou C, Taylor HR. The effect of sunglasses on ocular exposure to ultraviolet radiation. AJPH 1988 78(1) 72-74.

62. Dumbleton KA, Cullen AP, Doughty MJ. Protection from acute exposure to ultraviolet radiation by ultraviolet-absorbing RGP contact lenses. Ophthal Physiol Opt 199111 232-238.

63. Faubl H, Quinn MH. Methods for determining ultraviolet transmission of UV-blocking contact lenses. ICLC 199825 142-148.

64. Harris MG, Chin RS, Lee DS, Tam MH, Dobkins CE. Ultraviolet transmittance of the Vistakon disposable contact lenses. CLAO 200023 10-15.

65. Faubl H, Quinn MH. Spectra of UV-absorbing contact lenses: relative performance. ICLC 200027 65-74.

66. Chandler HI, Reuter KS, Sinnott LT, Nichols JJ. Prevention of UV-Induced Damage to the Anterior Segment Using Class I UV-Absorbing Hydrogel Contact Lenses. Invest Ophthalmol Vis Sci 201051 172-178.

67. Walsh JE, Bergmanson JPG, Koehler LV, Doughy MJ, Fleming DP, Harmey JR. Fibre optic spectrophotometry for the in vitro evaluation of ultraviolet radiation (UVR) spectral transmittance of rabbit corneas. Physiol Meas 200829 375-388.

68. DeLoss KS, Walsh JE, Bergmanson JPG. Current silicone hydrogel UVR blocking lenses and their associated protection factors. CLAE 2009 [Epub ahead of print].
69. Kwok LS, Kuznetsov VA, Ho A, Coroneo T. Prevention of the adverse photic effects of peripheral light-focusing using UV-blocking contact lenses. Invest Ophthalmol Vis Sci 200344 1501-1507.

70. Tønneson HH, Mathiesen S-ES, Karlsen J. Ultraviolet transmittance of monthly replacement lenses on the Scandinavian market. ICLC 199724 123-126. 